\title{
Numerical experiments in calculating snow water equivalent and estimating their impact on the formation of spring floods
}

\author{
Evgenii Churiulin ${ }^{1,2,{ }^{*},}$ Vladimir Kopeykin ${ }^{2}$, Natalia Frolova $^{1}$, and Inna Krylenko ${ }^{1}$ \\ ${ }^{1}$ Lomonosov Moscow State University, Leninskiye Gory 1, 119991, Moscow, Russia \\ ${ }^{2}$ Hydrometcenter of Russia, 11-13 Bolshoy Predtechensky per., 123242, Moscow, Russia
}

\begin{abstract}
Seasonal snow cover has a significant impact on forming spring floods. Sparse snow course-measuring network does not meet the requirements of modern tasks related to the technologies of numerical weather prediction (NWP) systems and runoff formation models. Moreover, insufficient volume of hydrometeorological data creates a need to improve spring floods forecasting methods by means of available modern hydrometeorological information related to snow cover. To work out an efficient solution to the issue of initial snow data preparation we need a complex approach including the use of data from satellite, atmospheric models, physical-mathematical models of snow cover and insitu information. This approach will provide modern NWP and hydrological models with reliable initial data on snow cover (snow water equivalent - SWE, snow density - SD). The main purpose of our investigation is related to approbation of satellite data and development of snow cover calculation methods for NWP and hydrological models. Numerous SWE and SD experiments have been performed in order to achieve this aim. A regional snow data assimilation system for COSMO$\mathrm{Ru}$ was implemented during the research. Moreover, a new method of hydrological modelling of spring floods based on ECOMAG model with initial information from COSMO-Ru, SnoWE and in-situ data has been proposed and tested.
\end{abstract}

\section{Applying NWP system COSMO-Ru and snow cover model SnoWE for forecasting spring floods}

Seasonal snow cover is an important resource of spring river supply on the territory of the Russian Federation. Moreover, snow forms spring floods. However, there is a problem of insufficient amount of hydrometeorological data which is related to the sparse snow coursemeasuring network. Because of it, hydrologists apply satellite data obtained from snow cover and numerical weather prediction models (NWP) for calculating spring floods. Nevertheless, in this case there is a problem with the accuracy of initial snow data applied in hydrological models. In this situation, an efficient solution for snow initial data preparation is a complex approach including the application of data from satellite,

\footnotetext{
* Corresponding author: evgenychur@gmail.com
} 
atmospheric models, physical-mathematical models of snow cover and in-situ information. This approach will make it possible to provide modern NWP and hydrological models with reliable initial data on snow cover (snow water equivalent - SWE, snow density - SD).

The main purpose of this research work is related to assessing the possibilities of applying the results of snow cover characteristics modelling (SWE and SD) for calculating water discharges during spring floods from 2013 to 2019 at streamflow measuring station the Sukhona River - v. Kalikino. The Sukhona is a river in the European part of Russia, a tributary of the Northern Dvina river. It is 558 kilometers long, and the area of its basin 50300 square kilometers. The Sukhona river joins the Yug river near the town of Veliky Ustyug, forming the Northern Dvina [1]. The results of calculating snow cover characteristics were obtained using the COSMO-Ru NWP system [2] and the snow cover model SnoWE $[3,4]$. In turn, hydrological modelling of spring floods was calculated using the runoff formation model ECOMAG $[5,6]$.

The most promising method for the analysis of spring flood characteristics is the method of synthesizing models of the hydrometeorological cycle (hydrological, meteorological and snow models). They range from the models obtaining the initial meteorological data (global and mesoscale atmospheric circulation models) to the models of runoff formation which allow to calculate the water inflow into the river network and the flow conditions in specific sections of the river. The articles [4,7] contain more detailed information about: a) synthesizing method of hydrometeorological models; b) the COSMO-Ru NWP system, the SnoWE and the ECOMAG models; c) the information about verification and calibration of these models; d) the first results of modelling spring floods characteristics based on synthesizing method.

The initial results of the implementation of such synthesized approach show that, in general, being based on the data from the COSMO-Ru NWP system, the ECOMAG model can reproduce main features of flow hydrographs for spring floods (Fig. 1). Especially important for the development of this method is the good correspondence of the hydrographs modeled according to the data from meteorological stations and the COSMO-Ru NWP system. The Nash Sutcliffe efficiency coefficient for streamflow measuring station from 2013 to 2017 (excluding 2014, when COSMO-Ru data on snow accumulation period was absent) was 0.44 when calculated on the basis of the data from the COSMO-Ru NWP system, and 0.62 when calculated using the in-situ data from meteorological stations [4].

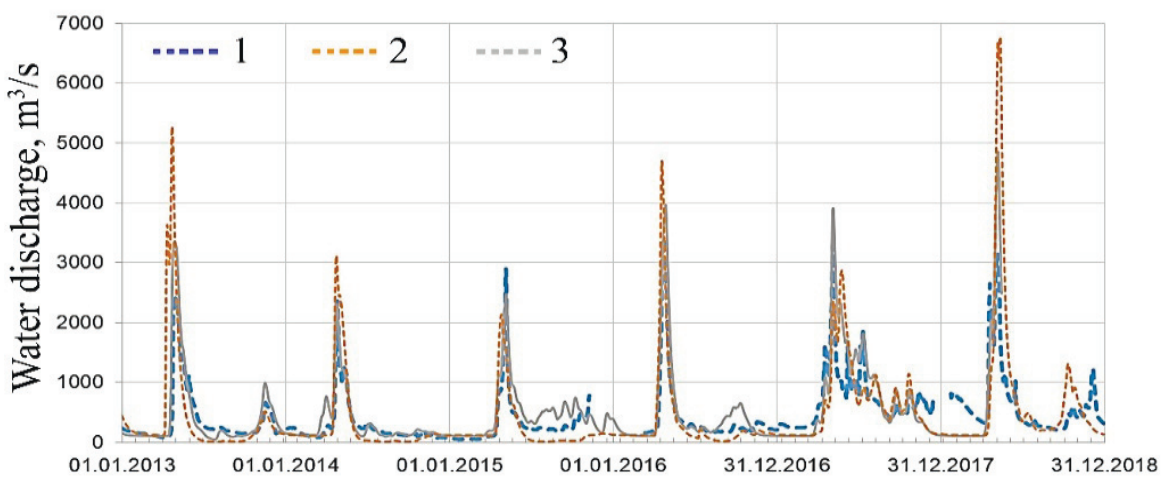

Fig. 1. Streamflow hydrographs at the Sukhona river - v. Kalikino: 1,2 - modeled on the basis of the ECOMAG model according to meteorological stations (coefficient of Nash Sutcliffe - NSE $=0,62$ ) and COSMO-Ru NWP system data (NSE $=0,44) ; 3$ - observed hydrographs.

In this investigation, a series of experiments has been performed. In the course of the experiments the working capacity of the snow cover parameterization scheme of the 
ECOMAG model (according to in-situ data from meteorological stations (SYNOP) and according to the COSMO-Ru NWP system data along with global data assimilation snow system) was compared with independent results of the snow cover model SnoWE and in-situ snow courses data. For estimation of the working capacity of the ECOMAG model 21 meteorological stations were selected. The stations were located in the catchment area of the North Dvina river. The period of comparison was 8 years from 2011 to 2019. All in all, 147 cases with information about SWE were formed for estimating and comparing.

Statistical analysis of data demonstrated that the SnoWE calculation results were more accurate in $90 \%$ of field snow courses cases and in $50 \%$ of forest snow courses cases than the results of the ECOMAG snow parameterization scheme (Fig. 2). In turn, the snow calculation results of the ECOMAG snow scheme along with in-situ meteorological data are accurate than the SnoWE in 10\% of field and 50\% of forest snow courses cases. At the same time, the results of SWE and SD calculations based on the ECOMAG model according to the COSMO-Ru NWP system data demonstrated significant overstatement of calculation results. It was found out that the significant overstatement of SWE and SD parameters of snow cover is related to accumulation of errors in model precipitations coming from the COSMO-Ru NWP system.

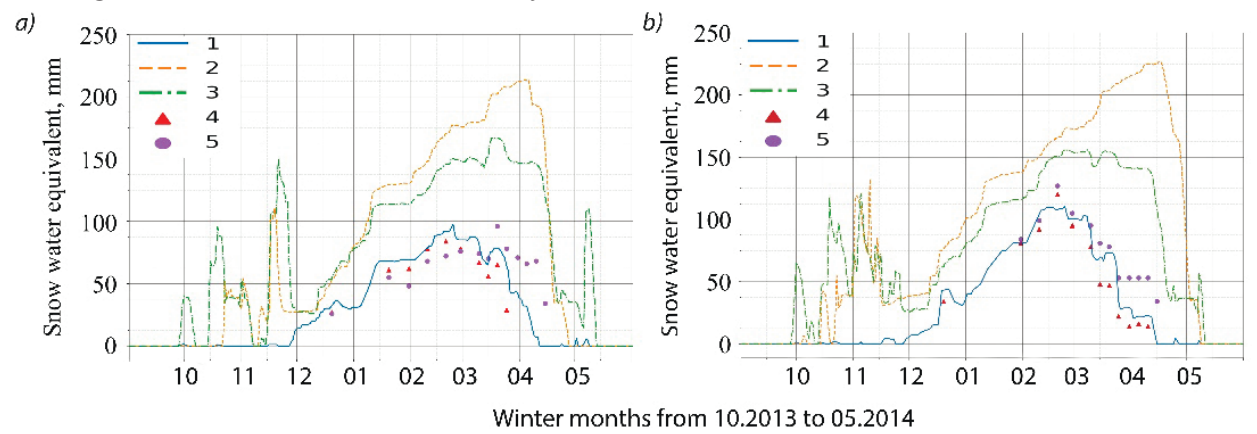

Fig. 2. Comparison of plots of SWE calculations. 1 - the SnoWE model; 2 - the ECOMAG model with initial meteorological data from the COSMO-Ru NWP system; 3 - the ECOMAG model with initial meteorological data from meteorological stations; 4 - in-situ field snow courses; 5 - in-situ forest snow courses. a - meteorological station - Krasnoborsk; b - meteorological station - Velsk;

There are several methods which could allow to correct calculations of snow cover characteristics and improve the quality of water discharges modelling in spring flood periods without making significant changes in the snow parametrization scheme of the ECOMAG.

Clarification of streamflow modeling results based on the ECOMAG model were carried out by introducing the corrections to the initial meteorological data. The correction to meteorological data was carried out by means of the following three methods:

1. Correction of the initial snow meteorological data fields from the COSMO-Ru NWP system;

2. Correction of snow in-situ data from meteorological stations due to correction coefficients;

3. Correction of the initial snow data due to a complex approach based on the results of the regional snow data assimilation system and correction coefficient.

\subsection{Correction of the initial snow meteorological data fields from COSMO-Ru}

The results of numerical experiments of snow cover characteristics calculation have shown that the ECOMAG model overstates the values of SWE and SD parameters of the snow 
cover according to the COSMO-Ru NWP system data with the global snow data assimilation system. As a result, a correction method has been introduced, which is related to the clarification of the initial meteorological snow cover parameters fields in the COSMO-Ru NWP system. This correction was implemented by means of creating a regional snow data assimilation system (DAS) for the territory of Russia. The regional snow DAS includes: a) physical parameterization schemes from the snow cover model SnoWE for the first snow, wet snow falling, dry snow falling, snow blown, snow melting and subsidence and evaporation from the surface of the snow cover [3]; b) modules of preprocessing and postprocessing; c) objective analysis of the snow cover based on the successive-correction method; d) module of visualization of calculation results.

Implementation of the regional snow DAS in the COSMO-Ru NWP system made it possible to correct the forecasting fields related to surface air temperature and atmospheric precipitation. Additional numerical experiments with the ECOMAG and the COSMO-Ru NWP system were carried out after incorporating the regional snow DAS in the structure of the COSMO-Ru NWP system for winter and spring season 2018/2019 years. Despite the fact that the incorporation of the regional snow DAS allowed to improve the quality of SWE and SD calculations by the COSMO-Ru NWP system, the quality of water discharges calculated by the ECOMAG worsened (Fig. 3, NSE $=-0,35$ ). The results of streamflow calculation experiments demonstrated that it happened due to errors in concurrency between models. The main reason of errors was established. It is related to the fact that the implementation of the regional snow DAS in the COSMO-Ru influenced air temperature calculations and as a result melting of snow cover slowed down in comparison with the real melting rate. Nevertheless, there is a positive effect which is related to the working capacity of this bundle of various types models and we need to continue our work in this direction.

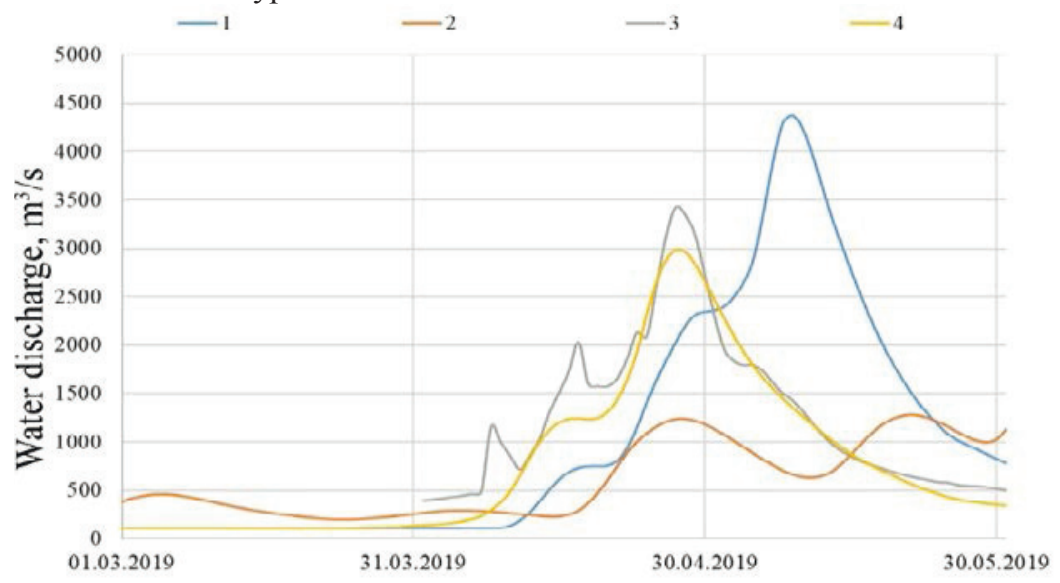

Fig. 3. Comparison of streamflow hydrographs at the Sukhona river - v. Kalikino for spring flood 2019: 1 - water discharges modeled on the basis of the ECOMAG model according to the COSMO-Ru data using global snow data assimilation system; 2 - according to the COSMO-Ru data using regional snow data assimilation system; 3 - according to in-situ data from meteorological stations; 4 - observed streamflow.

\subsection{Correction of snow in-situ data from meteorological stations due to correction coefficients}

The second method of the initial data correction is the application of correction coefficients. The correction coefficients were calculated by means of comparing snow water equivalent, snow density data from the snow cover model SnoWE and the runoff formation model 
ECOMAG according to in-situ data from meteorological stations, and the COSMO-Ru NWP system data. It should be noted that the catchment area of the North Dvina river is located on $90 \%$ in forest area. Because of this fact, the correction coefficients were calculated only for meteorological stations and snow courses located in the forest.

During the period from 2014 to 2018 the correction coefficients were introduced into the ECOMAG model for meteorological stations only once a year before snow melting periods (March, 1 of each year). Moreover, the runoff (Fig. 4) and snow cover calculations by the ECOMAG model had been paused before introducing the correction coefficients and after that, the calculations continued. The results demonstrated that introducing the forest correction coefficients led to improving the quality of streamflow calculation. As a result, NSE coefficients were improved from 0.44 to 0.49 for the COSMO-Ru data using the global DAS and from 0.63 to 0.70 for the in-situ data from meteorological stations.

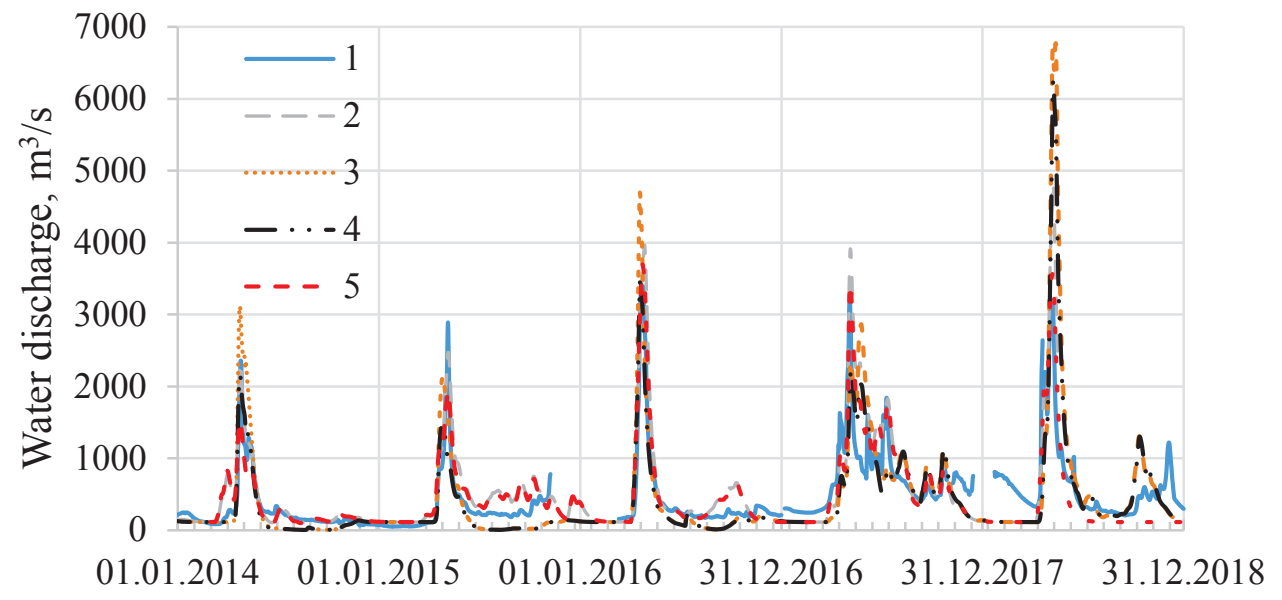

Fig. 4. Comparison of streamflow hydrographs at the Sukhona river - v. Kalikino for spring floods from 2014 to 2018: 1 - observed streamflow; water discharges modeled on the basis of the ECOMAG model: 2 - according to the COSMO-Ru data using the global snow DAS; 3 - according to the COSMO-Ru data using the global snow DAS and the correction coefficient; 4 - according to the insitu data from meteorological stations; 5 - according to the in-situ data from meteorological stations and correction coefficient.

\subsection{Correction of the initial snow data due to a complex approach based on work of the regional snow data assimilation system and correction coefficient}

The third correction method of the initial snow data is related to applying meteorological fields from the COSMO-Ru NWP system using the regional snow DAS and the subsequent correction coefficient, which are applied for each grid points of model grid (in our case the COSMO-Ru NWP system). As a result, the third correction method allows to save full volume of available input meteorological data and decrease the values of correction coefficients. Numerical experiments have been conducted, but due to the fact that since the introduction of the regional snow DAS errors have appeared in final streamflow modelling results, they have been recognized as incorrect. Moreover, additional experiments are required after correcting issues related to the interaction between models.

Numerical experiments with the COSMO-Ru data based on the global DAS have shown minor improvement in the quality of calculations of spring floods water discharge. The 
values of NSE coefficients were improved from 0.44 to 0.46 for the COSMO-Ru NWP system data using the global DAS.

\section{Conclusions}

Numerical experiments have demonstrated that the third method of correction is the most promising direction for the future development of spring floods calculation methods in the conditions of insufficient volume of hydrometeorological information and the investigation has to be continued in this direction, as only this method allows to save the necessary volume of hydrometeorological data, correct the information in the COSMO-Ru grid points and take into account the role of surface in forming snow cover and spring floods characteristics.

The acknowledgments: The research is supported by the Russian Foundation for Basic Research, project 18-05-60021- Arctic.

\section{References}

1. Wikipedia. Europe. https://en.wikipedia.org/wiki/Sukhona_River (2019)

2. Consortium for small scale modelling. DWD. http://www.cosmo-model.org/ (2019)

3. E. Kazakova, M. Chumakov, I. Rozinkina, COSMO Newsletter. 13. 39 - 49 (2013)

4. E. Churiulin, I. Krylenko, N. Frolova, B. Belyaev, IOP Conference Series: EES. 263. $1-7$ (2019)

5. Y. Motovilov, L. Gottschalk, K. Engeland, A. Belokurov, Institute report series. 105. $1-88$ (1999)

6. I. Krylenko, Y. Motovilov, E. Antokhina, V. Zhuk, G. Surkova, IAHS Publications. 368. $156-161$ (2015)

7. E. Churiulin, I. Krylenko, N. Frolova, B. Belyaev, I. Rozinkina, Hydrometeorological research and forecasting. 371. $6-24$ (2019) 